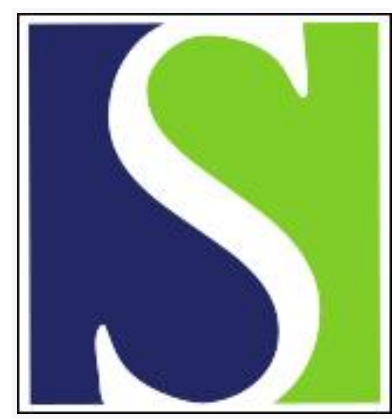

Scand J Work Environ Health 2012;38(6):546-552

https://doi.org/10.5271/sjweh.3279

Published online: 10 Feb 2012, Issue date: 01 Nov 2012

Cognitive function among sons of women who worked in dentistry

by Naimi-Akbar A, Sandborgh-Englund G, Ekbom A, Ekstrand J, Montgomery S

Affiliation: Aron Naimi-Akbar, Karolinska Institutet, Department of Dental Medicine, Box 4064, SE-141 04 Huddinge, Sweden. aron.naimi-akbar@ki.se

Refers to the following texts of the Journal: 1984;10(1):35-41 1999;25(3):285-290 2010;36(3):231-241 2011;37(6):539-546

Key terms: amalgam; cognitive function; dental nurse; dentist; dentistry; female dental personnel; mercury; occupational exposure; women

This article in PubMed: www.ncbi.nlm.nih.gov/pubmed/22517488

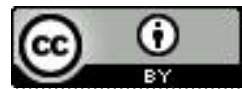




\title{
Cognitive function among sons of women who worked in dentistry
}

\author{
by Aron Naimi-Akbar, DDS, ${ }^{1}$ Gunilla Sandborgh-Englund, PhD, ${ }^{1}$ Anders Ekbom, PhD, ${ }^{2}$ Jan Ekstrand, PhD, ${ }^{2}$ \\ Scott Montgomery, PhD 2, 3, 4
}

\begin{abstract}
Naimi-Akbar A, Sandborgh-Englund G, Ekbom A, Ekstrand J, Montgomery S. Cognitive function among sons of women who worked in dentistry. Scand J Work Environ Health. 2012;38(6):546-552. doi:10.5271/sjweh.3279

Objective Exposure to elemental mercury vapor can impair neurological function as it is neurotoxic in doses higher than usually found in dentistry. Little is known about the potential effects of fetal exposure to elemental mercury among offspring of female dental workers. We investigated cognitive function among offspring of women working in dentistry at the time of their pregnancy.
\end{abstract}

Methods We compared results for cognitive function examinations taken by the majority of young men in Sweden at the time of compulsory military enlistment (age 17-18 years). Sons of female dentists ( $N=365)$ and dental nurses $(\mathrm{N}=3181)$ born during the $1960-1970$ s were compared with sons of female physicians $(\mathrm{N}=378)$ and assistant nurses $(\mathrm{N}=12$ 667).

Results Analysis by linear regression showed that sons of dental workers had similar or higher cognitive function test results compared to their matched cohorts.

Conclusion We found no evidence of poorer cognitive function among male offspring of female dentists or dental nurses.

Key terms amalgam; dental nurse; dentist; female dental personnel; mercury; occupational exposure.

Mercury is a toxic component of dental amalgam. The evidence of negative effects in offspring from occupational exposure in dentistry is limited and contradictory (1-5). Previous research has tended to focus on fertility and pregnancy outcomes $(1,3,5-6)$ rather than cognitive function, which is addressed in this study. Fetal mercury exposure may be a potential hazard for offspring of mothers working in dentistry who may be exposed to mercury due to their daily handling of amalgam. Such exposure to mercury is mainly through cord blood (7), where the magnitude of mercury concentration in maternal plasma is reflected by the magnitude of the fetal mercury concentration (7-9).

Dental personnel are still exposed to elemental mercury vapor when using dental amalgam even though this exposure used to be higher 20-30 years ago than it is today $(4,10-13)$. Pre-prepared capsules of dental amalgam were introduced in the 1980s, resulting in less mercury contamination in the working environment (14). In the 1960s and 1970s, before the capsules were introduced, mercury levels were higher, as indicated by the higher levels in dental workers' urine. During this period, mercury exposure levels were as high as levels that have been associated with non-specific symptoms of mercury intoxication $(4,11,15-16)$. Subtle health outcomes, such as mildly impaired cognitive function, have been reported in dentistry and other occupations with chronic exposure to elemental mercury vapor (17-19).

The purpose of this study was to investigate if there is impaired cognitive function in the male offspring of female dental workers. Mercury levels in dentistry during the study period were higher than are typical in Sweden today, although such relatively high levels continue to exist in dentistry in some other countries.

1 Division of Dental Biomaterials and Cariology, Department of Dental Medicine, Karolinska Institutet, Stockholm, Sweden.

2 Clinical Epidemiology Unit, Department of Medicine, Karolinska Institutet, Stockholm, Sweden.

3 Clinical Epidemiology and Biostatistics Unit, Örebro University Hospital, Örebro University, Örebro, Sweden.

4 The Department of Primary Care and Public Health, Charing Cross Hospital, Imperial College, London, UK. 


\section{Methods}

Two cohorts of boys potentially exposed to elemental mercury due to their mothers' occupation as a dentist or a dental nurse were compared with two matched cohorts of boys whose mothers worked as physicians or assistant nurses. All the boys were born between 1960-1978 when amalgam was still the main filling material in Swedish dentistry.

\section{Participants}

The occupations of women were identified using the Swedish Population and Housing Census (1960, 1970, 1980,1985 , and 1990) that provides occupation information at the time of the Census. Women identified as dentists or dental nurses for at least two consecutive census years were defined as being at greater risk of having an offspring exposed to mercury in utero if born during this period. These boys were identified using the MultiGeneration Register, which allows linkage between firstdegree relatives (20). Several subjects could be sons of the same mother. The boys in the exposed cohorts were individually matched with boys born during the same year, the mother of whom was the same age and working as physician or an assistant nurse. The matching ratio was planned as 1:5 and if we were not able to obtain this ratio, we selected all available subjects. Offspring of dentists were matched with offspring of physicians and those of dental nurses with assistant nurses' children.

\section{Outcome measures}

A cognitive function examination has been used at military enlistment since the 1940s in Sweden. Practically all able-bodied young men in Sweden took the tests during the study period, although some details of the examination altered over time (21).

\section{Enlistment battery 67 and enlistment battery 80}

Our main outcome measures were cognitive tests used until 1997 (known as enlistment battery 67 and enlistment battery 80 ), which were undertaken by conscripts born between 1960-1978. The examination consisted of four tests that we used separately as our outcome measures. Two tests assess linguistic understanding and the ability to use oral and written language. The first test (linguistic understanding 1) examined the conscript's ability to interpret and follow written instructions. The second test (linguistic understanding 2) examined the ability to identify synonyms. The third test (spatial recognition) examined the ability to visualize manipulation of objects mentally and recognize objects in different positions. The fourth test (technical comprehension) consisted of problems that could be solved with knowledge of mechanics and basic physics (21-24). Each test consisted of 40 units. The scores were transformed into a value on a normalized standard scale of nine units, with an average of five (21). In our analyses, we used the standardized scores ranging from 1-9 for each test.

\section{Potential confounding factors}

Father's educational attainment. The data were obtained from the Population and Housing Census of 1990. Information on education was divided into nine categories, based on the highest attained level of educational attainment for the father by the time of the census (table 1). If the data for the father's education were missing in the 1990 census, the category for "no information on level of education" was applied.

Older siblings. The Multi-Generation Register provided information about number and birth year of older siblings. The variable was dichotomized into having older siblings or not.

The mother's age at time of birth. This measure was dichotomized to identify mothers $\geq 25$ years or not.

Calendar period. The period when subjects were born in decades (1960s and 1970s).

\section{Statistical analysis}

We compared mean scores for the four components of enlistment batteries 67 and 80 . between the cohorts using linear regression, adjusted for father's educational level, mother's age at birth, older siblings, and decade of birth, modeled as series of dichotomous categorical variables.

The chi-squared test was used to identify differences between the cohorts for the proportion with missing outcome scores (enlistment batteries 67 and 80).

An approximation of maternal exposure prior to birth was based on how many years had elapsed between the first census in which the dentist or dental nurse was registered as a dentist or dental nurse and the time of delivery. This was categorized as higher ( $>5$ years) or lower exposure ( $\leq 5$ years).

In the cohorts of dental workers' sons, more than one son could have the same mother. Additional analyses were limited to the first born to individual mothers during the study period.

For all statistical analysis PASW Statistics 18 (IBM, Armonk, NY, USA) was used. P-values $<0.05$ and confidence intervals not including 0 were considered as statistically significant. 
Table 1. Cohort characteristics.

\begin{tabular}{|c|c|c|c|c|c|c|c|c|}
\hline & \multicolumn{8}{|c|}{ Mother's occupation } \\
\hline & \multicolumn{2}{|c|}{$\begin{array}{l}\text { Dentist } \\
\mathrm{N}=365\end{array}$} & \multicolumn{2}{|c|}{$\begin{array}{c}\text { Dental nurse } \\
\quad \mathrm{N}=3181\end{array}$} & \multicolumn{2}{|c|}{$\begin{array}{c}\text { Physician } \\
\mathrm{N}=378\end{array}$} & \multicolumn{2}{|c|}{$\begin{array}{l}\text { Assistant nurse } \\
\mathrm{N}=12667\end{array}$} \\
\hline & $\mathrm{N}$ & $\%$ & N & $\%$ & $\mathrm{~N}$ & $\%$ & N & $\%$ \\
\hline $\begin{array}{l}\text { Birth decade } \\
\text { 1960's } \\
\text { 1970's }\end{array}$ & $\begin{array}{l}142 \\
223\end{array}$ & $\begin{array}{l}38.9 \\
61.1\end{array}$ & $\begin{array}{l}1200 \\
1981\end{array}$ & $\begin{array}{l}37.7 \\
62.3\end{array}$ & $\begin{array}{l}126 \\
252\end{array}$ & $\begin{array}{l}33.3 \\
66.7\end{array}$ & $\begin{array}{l}4632 \\
8035\end{array}$ & $\begin{array}{l}36.6 \\
63.4\end{array}$ \\
\hline $\begin{array}{l}\text { Mother's age at subject's birth } \\
\leq 25 \\
26-34 \\
\geq 35\end{array}$ & $\begin{array}{r}3 \\
280 \\
82\end{array}$ & $\begin{array}{r}0.8 \\
76.7 \\
22.5\end{array}$ & $\begin{array}{r}1200 \\
1838 \\
143\end{array}$ & $\begin{array}{r}37.7 \\
57.8 \\
4.5\end{array}$ & $\begin{array}{r}2 \\
252 \\
124\end{array}$ & $\begin{array}{r}0.5 \\
66.7 \\
32.8\end{array}$ & $\begin{array}{r}5254 \\
6769 \\
644\end{array}$ & $\begin{array}{r}41.5 \\
53.4 \\
5.1\end{array}$ \\
\hline $\begin{array}{l}\text { Number of siblings } \\
0 \\
1-2 \text { siblings } \\
\geq 3 \text { siblings }\end{array}$ & $\begin{array}{r}224 \\
136 \\
5\end{array}$ & $\begin{array}{r}61.4 \\
37.3 \\
1.4\end{array}$ & $\begin{array}{r}1405 \\
1732 \\
44\end{array}$ & $\begin{array}{r}44.2 \\
54.4 \\
1.4\end{array}$ & $\begin{array}{r}183 \\
179 \\
16\end{array}$ & $\begin{array}{r}48.4 \\
47.4 \\
4.2\end{array}$ & $\begin{array}{r}5680 \\
6587 \\
400\end{array}$ & $\begin{array}{r}44.8 \\
52.0 \\
3.2\end{array}$ \\
\hline $\begin{array}{l}\text { Father's education } \\
\text { No education } \\
\text { Primary and lower secondary education ( }<9 \text { years) } \\
\text { Primary and lower secondary education ( } 9 \text { years) } \\
\text { Upper secondary education ( }<3 \text { years) } \\
\text { Upper secondary education ( } 3 \text { years) } \\
\text { Post-secondary education ( }<3 \text { years) } \\
\text { Post-secondary education ( }>3 \text { years) } \\
\text { Post-graduate education } \\
\text { No information about level of education }\end{array}$ & $\begin{array}{r}34 \\
10 \\
1 \\
1 \\
16 \\
12 \\
220 \\
32 \\
39\end{array}$ & $\begin{array}{r}9.3 \\
2.7 \\
0.3 \\
0.3 \\
4.4 \\
3.3 \\
60.3 \\
8.8 \\
10.7\end{array}$ & $\begin{array}{r}42 \\
727 \\
271 \\
380 \\
694 \\
386 \\
424 \\
22 \\
235\end{array}$ & $\begin{array}{r}1.3 \\
22.9 \\
8.5 \\
11.9 \\
21.8 \\
12.1 \\
13.3 \\
0.7 \\
7.4\end{array}$ & $\begin{array}{r}40 \\
2 \\
1 \\
6 \\
8 \\
12 \\
153 \\
102 \\
54\end{array}$ & $\begin{array}{r}10.6 \\
0.5 \\
0.3 \\
1.6 \\
2.1 \\
3.2 \\
40.5 \\
27.0 \\
14.3\end{array}$ & $\begin{array}{r}314 \\
4928 \\
1279 \\
1871 \\
1744 \\
935 \\
502 \\
19 \\
1075\end{array}$ & $\begin{array}{r}2.5 \\
38.9 \\
10.1 \\
14.8 \\
13.8 \\
7.4 \\
4.0 \\
0.1 \\
8.5\end{array}$ \\
\hline
\end{tabular}

\section{Ethics}

The Stockholm Ethical Review Board granted ethical approval to the study.

\section{Results}

The dentist cohort consisted of 365 sons of female dentists born between 1960-1978; the dental nurse cohort comprised 3181 sons, the physician cohort 378 sons, and the assistant nurse cohort 12667 sons (table 1). The planned ratio (for dentists to physicians and dental nurse to assistant nurse) of 1:5 was not achieved, because it was not possible to find the number initially planned.

In the univariate analysis, the dentist cohort had slightly lower scores compared with the physician cohort for all four cognitive tests, but none of these differences were statistically significant. The dental nurse cohort had significantly higher scores $(\mathrm{P}<0.001)$ than the assistant nurse cohort for all four cognitive tests (tables $2 \mathrm{a}$ and $2 \mathrm{~b}$ ). The results were almost unaltered after adjustment for father's educational level, mother's age at time of birth, presence of older siblings and decade of birth (tables $2 \mathrm{a}$ and $2 \mathrm{~b}$ ). Differences between the dentist and physician cohorts were not statistically significant after adjustment (tables $2 \mathrm{a}$ and $2 \mathrm{~b}$ ).

We assessed the statistical power to detect poorer cognitive function test scores among sons of dentists compared with sons of physicians. In a post hoc power calculation [for $80 \%$ power and $95 \%$ confidence intervals $(95 \% \mathrm{CI})]$ based on the physician cohort scores and the existing sample sizes, we had sufficient power to detect lower scores among the dentists of the following magnitude: 0.32 for "linguistic understanding 1 ", 0.32 for "linguistic understanding 2", 0.36 for "spatial recognition", and 0.37 for "technical comprehension".

There was clear evidence of an association between paternal educational attainment and cognitive function scores among offspring. Among the dental nurse and assistant nurse cohorts, higher levels of paternal education were statistically significantly associated with better cognitive function scores. When compared with upper secondary education $<3$ years, upper secondary education $>3$ years among fathers was associated with higher scores among offspring demonstrated by regression coefficients (and 95\% CI) for the four tests of 0.82 (95\% CI 0.68-0.96), 0.80 (95\% CI 0.67-0.93), 0.62 (95\% CI $0.47-0.76)$, and 0.62 (95\% CI $0.48-0.76)$. The results among the dentist and physician cohorts for the same tests were: $1.29(95 \%$ CI $0.11-2.48), 1.32(95 \% \mathrm{CI}$ $0.20-2.45), 1.23$ (95\% CI -0.042-2.50), and $1.50(95 \%$ CI 0.25-2.75).

Not all the potential subjects participated in military enlistment or completed the cognitive tests. There was some minor variation between cohorts in the percentage that had cognitive test results, ranging from $87.1-90.0 \%$. 
Table 2a. Cognitive function tests scores for sons of female dentists compared with sons of female physicans. Mean scores are for the four cognitive test components, with standard error (SE), unadjusted and adjusted regression coefficients with $95 \%$ confidence intervals $(95 \% \mathrm{Cl})$ and P-values.

\begin{tabular}{|c|c|c|c|c|c|c|c|c|c|c|}
\hline \multirow[t]{2}{*}{ Test component } & \multicolumn{2}{|c|}{$\begin{array}{l}\text { Dentist } \\
(\mathrm{N}=365)\end{array}$} & \multicolumn{2}{|c|}{$\begin{array}{c}\text { Physician } \\
(\mathrm{N}=378)\end{array}$} & \multicolumn{3}{|c|}{ Unadjusted } & \multicolumn{3}{|c|}{ Adjusted $^{\text {a }}$} \\
\hline & Mean & SE & Mean & SE & $\begin{array}{l}\text { Regression } \\
\text { coefficient }\end{array}$ & $95 \%$ & P-value & $\begin{array}{c}\text { Regression } \\
\text { coefficient }\end{array}$ & $95 \% \mathrm{Cl}$ & P-value \\
\hline Linguistic understanding 1 & 6.87 & 0.08 & 6.91 & 0.08 & -0.033 & $-0.263-0.196$ & 0.775 & 0.085 & $-0.156-0.325$ & 0.489 \\
\hline Linguistic understanding 2 & 6.63 & 0.08 & 6.84 & 0.08 & -0.210 & $-0.427-0.006$ & 0.056 & -0.121 & $-0.348-0.106$ & 0.296 \\
\hline Spatial recognition & 6.60 & 0.09 & 6.63 & 0.09 & -0.031 & $-0.274-0.212$ & 0.802 & -0.013 & $-0.271-0.245$ & 0.920 \\
\hline Technical comprehension & 6.58 & 0.09 & 6.64 & 0.09 & -0.060 & $-0.302-0.181$ & 0.624 & -0.015 & $-0.270-0.239$ & 0.905 \\
\hline
\end{tabular}

a Regression coefficients adjusted for the father's educational level, the mother's age at time of birth, if they had older siblings and what decade they were born.

Table 2b. Cognitive function tests scores for sons of female dentistal nurses compared with sons of female assistants nurses. Mean scores are for the four cognitive test components, with standard error (SE), unadjusted and adjusted regression coefficients with $95 \%$ confidence intervals $(95 \% \mathrm{Cl})$ and P-values.

\begin{tabular}{|c|c|c|c|c|c|c|c|c|c|c|}
\hline \multirow[t]{2}{*}{ Test component } & \multicolumn{2}{|c|}{$\begin{array}{l}\text { Dental nurse } \\
(\mathrm{N}=3181)\end{array}$} & \multicolumn{2}{|c|}{$\begin{array}{l}\text { Assistant nurse } \\
(\mathrm{N}=12667)\end{array}$} & \multicolumn{3}{|c|}{ Unadjusted } & \multicolumn{3}{|c|}{ Adjusted a } \\
\hline & Mean & SE & Mean & SE & $\begin{array}{l}\text { Regression } \\
\text { coefficient }\end{array}$ & $95 \% \mathrm{Cl}$ & P-value & $\begin{array}{l}\text { Regression } \\
\text { coefficient }\end{array}$ & $95 \% \mathrm{Cl}$ & P-value \\
\hline Linguistic understanding 1 & 5.52 & 0.03 & 4.91 & 0.02 & 0.610 & $0.539-0.681$ & 0.000 & 0.432 & $0.360-0.503$ & 0.000 \\
\hline Linguistic understanding 2 & 5.38 & 0.03 & 4.79 & 0.01 & 0.593 & $0.528-0.658$ & 0.000 & 0.420 & $0.354-0.485$ & 0.000 \\
\hline Spatial recognition & 5.34 & 0.03 & 4.86 & 0.02 & 0.478 & $0.406-0.550$ & 0.000 & 0.327 & $0.254-0.401$ & 0.000 \\
\hline Technical comprehension & 5.35 & 0.03 & 4.88 & 0.02 & 0.473 & $0.403-0.543$ & 0.000 & 0.326 & $0.255-0.397$ & 0.000 \\
\hline
\end{tabular}

${ }^{a}$ Regression coefficients adjusted for the father's educational level, the mother's age at time of birth, if they had older siblings and what decade they were born.

There were no statistically signific ant differences for proportions with test results between the cohorts of sons of dental personnel and their comparators.

We compared cognitive test scores among the two cohorts of boys with mothers who worked in dentistry and examined those categorized as high and low exposure (duration of maternal employment prior to delivery) using linear regression, with adjustment for father's educational level, mother's age at time of birth, presence of older siblings, and decade of birth. In the two cohorts of offspring of female dental workers, there was no association between duration working in dentistry prior to delivery and the test scores. The largest differences - although not statistically significant - were observed among offspring of dental nurses, for the technical comprehension test: the mean score for those with mothers working in dentistry for $<5$ years was 5.32, and the score was 5.41 for those with mothers who worked for longer. Adjustment for the potential confounding factors made no material difference to the results for any of the cohorts (data not shown).

The same female dental worker could have contributed more than one offspring to the study. Therefore, additional analysis excluded all but the first son born during the study period. After limiting the analysis to one son per mother in the entire cohort, the results did not differ notably to those from the main analysis (data not shown).

\section{Discussion}

This study compared cognitive function in cohorts potentially exposed to mercury in early life through a maternal occupation in dentistry, with comparison cohorts of subjects whose mothers did not work in dentistry. Our results show that sons of dental workers had similar or higher cognitive function test results in relation to their comparison cohorts. To tackle potential bias due to educational and material differences associated with parental occupation, we created comparison cohorts of boys born to mothers that had occupations similar to the dental workers: physicians for dentists and assistant nurses for dental nurses.

The sons of dentists had somewhat lower average cognitive function scores than the sons of physicians, but adjustment, particularly for father's education, attenuated or reversed the direction of the differences between the cohorts. This suggests that the variation in cognitive function between the cohorts is largely explained by dif- 
ferences in parental and familial characteristics, rather than maternal exposures associated with dentistry. This assertion is supported by comparison of the dental nurses' sons, who had higher cognitive function scores than the assistant nurses' children. Again, this difference is likely to be explained by familial differences rather than employment-related maternal exposures as the estimate of difference was again attenuated by adjustment for father's educational attainment.

Our results demonstrate that parent's educational level was strongly associated with the son's results. We also adjusted for other confounding factors such as mother's age and the presence of older siblings. We did not adjust for maternal educational level since it is too collinear with the mother's employment (the exposure measure) to include it in the regression models.

Potentially harmful mercury levels, with median urinary levels of approximately $20-50 \mu \mathrm{g} / \mathrm{l}$, were common among dental personnel during 1960-1970s (15). There are other occupations than dentistry that can result in exposure to elemental mercury, such as chloralkali industries (electrolysis of sodium chloride solution) and cinnabar mining (25). Adverse effects on neurological function, such as impaired motor skills and reduced cognitive function, have been found among workers in these occupations (25-27). Adverse neurological effects among children, due to exposures associated with small-scale gold mining, have been reported at a median urinary mercury level of $10.05 \mu \mathrm{g} / \mathrm{l}$ (26). There seems to be a dose-dependent relationship, where the level of exposure is reflected by the magnitude of adverse effects, but it is unclear at what exposure level adverse effects begin to occur $(18,28)$. Since elemental mercury can pass the placenta, it constitutes a potential hazard for the fetus if the mother's blood mercury levels are increased $(7,9,11,14,29)$.

The cognitive tests we used as our main outcome measures have been used in other studies to show adverse effects from ionizing radiation (30) so they are sensitive markers of environmental exposures. Studies of exposure to dental amalgam fillings among children did not observe any inverse associations with cognitive function (31-32) neither did our study of another potential exposure route: in utero, due to maternal employment in dentistry.

Although the cohorts were defined retrospectively, all of the register data measuring exposure, outcome, and potential confounding factors were recorded prospectively, thus eliminating error associated with recall bias.

The social and economic differences between the cohorts are unlikely to mask an important association, particularly since we were able to adjust for several relevant potential confounding factors and mothers were selected for similarity of profession (and thus background). There are probably other social factors that influence how young men perform in cognitive function tests, and this could potentially be a limitation of the validity of the results. This might theoretically mask subtle differences in cognitive function due to mercury exposure in utero; however, given our results, such differences could only be negligible in magnitude. There is a possibility that mothers who were dental workers stopped working early in the pregnancy, but as the half-life of inorganic mercury is about 60 days (33-34), this makes it likely that the mercury levels would still have been increased at least during the early stages of the pregnancy.

As mercury can accumulate in human tissue, we examined duration of maternal employment in dentistry for evidence of an effect of longer-term exposure to mercury compounds. Again, this analysis provided no evidence of risk associated with mothers who had worked in dentistry for a longer period before pregnancy. A limitation of these results is the lack of information of potential exposure data before 1960 and that the information on working in dentistry was recorded with 10-year gaps, introducing the risk of exposure misclassification. Any major risks are still likely to have been found even with these limitations, even though small differences may theoretically be masked.

While we are confident that virtually all male subjects potentially exposed during the study period are included in our study, we could not examine outcomes among females as they are not included in the enlistment registers. If girls are more sensitive to mercury exposure effects on neural development, our study could not identify it. As we did not examine pregnancy outcome and our results are selected for live births, any offspring lost during pregnancy was not included in the study. Subjects with very poor health or disability in any of the cohorts will probably not have been included in our analyses as they would have been unlikely to enter the military enlistment process: our results are valid for those healthy enough to participate at military enlistment. This seems unlikely to have masked an effect of maternal dental employment, as the proportions of subjects who did not complete the cognitive test or participate in military enlistment were not significantly different between the cohorts.

We found no evidence that male offspring of female dental workers in Sweden suffered from impaired cognitive function. Our results indicate that there was no increased risk for such teratogenic effects during our study period, when the levels of elemental mercury in dentistry were much higher than in Sweden today, indicating that an increased risk in modern dentistry is highly unlikely. In some parts of the world where mercury exposure associated with amalgam use is at similarly high levels as our study period, these results suggest that related occupational exposure among female dental workers will not adversely influence cognitive function among their offspring. 


\section{Acknowledgements}

This study was supported by grants from Karolinska Institutet, the National Board of Health and Welfare and the Swedish Society of Medicine. The authors declare no conflict of interest.

\section{References}

1. Lindbohm ML, Ylostalo P, Sallmen M, Henriks-Eckerman ML, Nurminen T, Forss H, et al. Occupational exposure in dentistry and miscarriage. Occup Environ Med. 2007;64(2):127-33. http://dx.doi.org/10.1136/oem.2005.026039.

2. Ericson A, Kallen B. Pregnancy outcome in women working as dentists, dental assistants or dental technicians. Int Arch Occup Environ Health. 1989;61(5):329-33. http://dx.doi. org/10.1007/BF00409388.

3. Jones L, Bunnell J, Stillman J. A 30-year follow-up of residual effects on New Zealand School Dental Nurses, from occupational mercury exposure. Hum Exp Toxicol. 2007;26(4):367-74. http://dx.doi.org/10.1177/0960327107076824.

4. Baelum J, Pöckel H. Reference document on exposure to metallic mercury and the development of symptoms with emphasis on neurological and neuropsychological diseases or complaints. Odense: Department of Occupational and Environmental Medicine, Odense University Hospital; 2007.

5. Heggland I, Irgens A, Tollanes M, Romundstad P, Syversen T, Svendsen K, et al. Pregnancy outcomes among female dental personnel--a registry-based retrospective cohort study. Scand J Work Environ Health. 2011;37(6):539-46. http://dx.doi. org/10.5271/sjweh.3175.

6. Dahl JE, Sundby J, Hensten-Pettersen A, Jacobsen N Dental workplace exposure and effect on fertility. Scand J Work Environ Health. 1999;25(3):285-90. http://dx.doi. org/10.5271/sjweh.436.

7. Bjornberg KA, Vahter M, Berglund B, Niklasson B, Blennow M, Sandborgh-Englund G. Transport of methylmercury and inorganic mercury to the fetus and breast-fed infant. Environ Health Perspect. 2005;113(10):1381-5. http://dx.doi. org/10.1289/ehp.7856.

8. Palkovicova L, Ursinyova M, Masanova V, Yu Z, HertzPicciotto I. Maternal amalgam dental fillings as the source of mercury exposure in developing fetus and newborn. J Expo Sci Environ Epidemiol. 2008;18(3):326-31. http://dx.doi. org/10.1038/sj.jes.7500606.

9. Sandborgh-Englund G, Ask K, Belfrage E, Ekstrand J. Mercury exposure in utero and during infancy. J Toxicol Environ Health A. 2001;63(5):317-20. http://dx.doi. org/10.1080/15287390152103634.

10. Ritchie KA, Burke FJ, Gilmour WH, Macdonald EB, Dale IM, Hamilton RM, et al. Mercury vapour levels in dental practices and body mercury levels of dentists and controls. Br Dent J. 2004;197(10):625-32; discussion 21. http://dx.doi. org/10.1038/sj.bdj.4811831

11. Horsted-Bindslev P. Amalgam toxicity--environmental and occupational hazards. J Dent. 2004;32(5):359-65. http:// dx.doi.org/10.1016/j.jdent.2004.02.002.

12. Stone ME, Cohen ME, Debban BA. Mercury vapor levels in exhaust air from dental vacuum systems. Dent Mater. 2007;23(5):527-32. http://dx.doi.org/10.1016/j. dental.2006.03.011.

13. JokstadA. Mercury excretion and occupational exposure of dental personnel. Community Dent Oral Epidemiol. 1990;18(3):1438. http://dx.doi.org/10.1111/j.1600-0528.1990.tb00040.x.

14. Svendsen K, Syversen T, Melo I, Hilt B. Historical exposure to mercury among Norwegian dental personnel. Scand J Work Environ Health. 2010;36(3):231-41. http://dx.doi. org/10.5271/sjweh.2878.

15. Lenvik K, Woldbæk T, Halgard K. Kvikksølveksponering blant tannhelsepersonell: en presentasjon av historiske måledata [Exposure to mercury among dental personnel: a presentation of historic measurement data; English summary]. Nors Tannlegeforenings Tid. 2006;116(6):350-6.

16. Echeverria D, Heyer NJ, Martin MD, Naleway CA, Woods JS, Bittner AC, Jr. Behavioral effects of low-level exposure to elemental $\mathrm{Hg}$ among dentists. Neurotoxicol Teratol. 1994;17(2):161-8. http://dx.doi.org/10.1016/08920362(94)00049-J.

17. Echeverria D, Woods JS, Heyer NJ, Rohlman DS, Farin FM, Bittner AC, Jr., et al. Chronic low-level mercury exposure, BDNF polymorphism, and associations with cognitive and motor function. Neurotoxicol Teratol. 2005;27(6):781-96. http://dx.doi.org/10.1016/j.ntt.2005.08.001

18. Meyer-Baron M, Schaeper M, Seeber A. A meta-analysis for neurobehavioural results due to occupational mercury exposure. Arch Toxicol. 2002;76(3):127-36. http://dx.doi. org/10.1007/s00204-002-0327-9.

19. Ritchie KA, Gilmour WH, Macdonald EB, Burke FJ, McGowan DA, Dale IM, et al. Health and neuropsychological functioning of dentists exposed to mercury. Occup Environ Med. 2002;59(5):287-93. http://dx.doi.org/10.1136/ oem.59.5.287.

20. Ekbom A. The Swedish Multi-generation Register. Methods Mol Biol. 2011;675:215-20. http://dx.doi.org/10.1007/9781-59745-423-0_10.

21. Carlstedt B. Cognitive abilities - aspects of structure, process and measurement [dissertation] Gothenburg: University of Gothenburg; 2000.

22. David AS, Malmberg A, Brandt L, Allebeck P, Lewis G IQ and risk for schizophrenia: a population-based cohort study. Psychol Med. 1997;27(6):1311-23. http://dx.doi. org/10.1017/S0033291797005680.

23. Hemmingsson T, Kriebel D, Melin B, Allebeck P, Lundberg I. How does IQ affect onset of smoking and cessation of smoking--linking the Swedish 1969 conscription cohort to the Swedish survey of living conditions. Psychosom Med. 2008;70(7):805-10. http://dx.doi.org/10.1097/ PSY.0b013e31817b955f. 
24. Zammit S, Allebeck P, David AS, Dalman C, Hemmingsson $\mathrm{T}$, Lundberg I, et al. A longitudinal study of premorbid IQ Score and risk of developing schizophrenia, bipolar disorder, severe depression, and other nonaffective psychoses. Arch Gen Psychiatry. 2004;61(4):354-60. http://dx.doi.org/10.1001/ archpsyc.61.4.354.

25. ATSDR. Toxicological Profile for Mercury. Atlanta, GA: Agency for Toxic Substances and Disease Registry; 1999. 26. Bose-O'Reilly S, Lettmeier B, Gothe RM, Beinhoff C, Siebert U, Drasch G. Mercury as a serious health hazard for children in gold mining areas. Environ Res. 2008;107(1):8997. http://dx.doi.org/10.1016/j.envres.2008.01.009.

27. Piikivi L, Hanninen H, Martelin T, Mantere P. Psychological performance and long-term exposure to mercury vapors. Scand J Work Environ Health. 1984;10(1):35-41. http://dx.doi. $\operatorname{org} / 10.5271 /$ sjweh.2365.

28. Meyer-Baron M, Schaeper M, van Thriel C, Seeber A. Neurobehavioural test results and exposure to inorganic mercury: in search of dose-response relations. Arch Toxicol. 2004;78(4):207-11. http://dx.doi.org/10.1007/s00204-0030531-2.

29. Ask K, Akesson A, Berglund M, Vahter M. Inorganic mercury and methylmercury in placentas of Swedish women. Environ Health Perspect. 2002;110(5):523-6. http://dx.doi. org/10.1289/ehp.02110523.
30. Hall P, Adami HO, Trichopoulos D, Pedersen NL, Lagiou $\mathrm{P}$, Ekbom A, et al. Effect of low doses of ionising radiation in infancy on cognitive function in adulthood: Swedish population based cohort study. BMJ. 2004;328(7430):19. http://dx.doi.org/10.1136/bmj.328.7430.19.

31. Bellinger DC, Daniel D, Trachtenberg F, Tavares M, McKinlay S. Dental amalgam restorations and children's neuropsychological function: The New England children's amalgam trial. Environ Health Perspect. 2006;115(3):440-46. http://dx.doi.org/10.1289/ehp.9497.

32. Bellinger DC, Trachtenberg F, Daniel D, Zhang A, Tavares MA, McKinlay S. A dose-effect analysis of children's exposure to dental amalgam and neuropsychological function - The new England children's amalgam trial. J Am Dent Assoc. 2007;138(9):1210-16.

33. Clarkson TW. The three modern faces of mercury. Environ Health Perspect. 2002;110 Suppl 1:11-23. http://dx.doi. org/10.1289/ehp.02110s111.

34. WHO. Concise international chemical assessment document 50. Elemental mercury and inorganic compounds: Human health aspects. Geneva: WHO; 2003.

Received for publication: 1 September 2011 